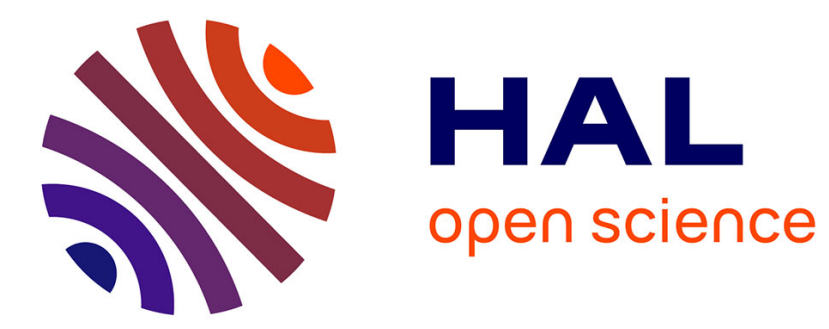

\title{
RECHERCHES SUR L'IRRADIATION DES MILIEUX NUTRITIFS BACTÉRIOLOGIQUES PAR LES RAYONS ULTRA-VIOLETS.
}

\author{
Josef Proks
}

\section{- To cite this version:}

Josef Proks. RECHERCHES SUR L'IRRADIATION DES MILIEUX NUTRITIFS BACTÉRIOLOGIQUES PAR LES RAYONS ULTRA-VIOLETS.. Le Lait, 1933, 13 (123), pp.331-337. hal00895101

\section{HAL Id: hal-00895101 \\ https://hal.science/hal-00895101}

Submitted on 1 Jan 1933

HAL is a multi-disciplinary open access archive for the deposit and dissemination of scientific research documents, whether they are published or not. The documents may come from teaching and research institutions in France or abroad, or from public or private research centers.
L'archive ouverte pluridisciplinaire HAL, est destinée au dépôt et à la diffusion de documents scientifiques de niveau recherche, publiés ou non, émanant des établissements d'enseignement et de recherche français ou étrangers, des laboratoires publics ou privés. 


\title{
RECHERCHES SUR L'IRRADIATION DES MILIEUX NUTRITIFS BACTÉRIOLOGIQUES PAR LES RAYONS ULTRA-VIOLETS.
}

\author{
par le Dr Josef PROKS
}

Directeur de l'Institut lactologique de l'Ecole des hautes études agronomiques à Brno.

(Travail de l'Institut lactologique de l'Ecole polytechnique tchèque, à Prague.)

On sait, depuis les recherches de BucHner (1) et d'autres auteurs, que la lumière exerce une influence défavorable sur le développement des bactéries. DIEUdonné a constaté que cette influence nuisible augmente avec la diminution de la longueur des ondes lumineuses. Il semble donc, d'après cela, que l'effet sur le développement des bactéries sera maximum en utilisant les rayons ultra-violets.

On a cherché aussi à utiliser ces qualités des rayons ultraviolets pour la destruction des bactéries dans le lait. M. SEIFFERT (2) a construit, le premier, un appareil pour l'irradiation du lait, un appareil destiné à en détruire les bactéries par l'utilisation de ces radiations. Partant de ces recherches, d'autres auteurs (WoLf, Thiele, Oelschlager, Schultz, etc.) ont cherché à leur tour à débarrasser le lait de ses bactéries par l'effet des rayons ultraviolets, mais les résultats obtenus dans ces recherches n'ont pas été tels qu'on ait pu songer, commercialement, à remplacer les procédés de pasteurisation par l'irradiation du lait.

Quoi qu'il en soit, il semble bien démontré que l'irradiation par les rayons ultra-violets exerce une influence nuisible sur les bactéries. Cette influence paraît se faire sentir aussi, sur quelques milieux nutritifs, de telle manière qu'elle rendrait le milieu considéré moins favorable à la multiplication des organismes. Pour élucider cette question, j'ai entrepris une série d'essais sur l'irradiation des milieux nutritifs bactériologiques, afin de constater dans quelle mesure se produisent ces modifications dans leur aptitude à la culture des bactéries. Une petite lampe de MüLLER, dite analytique, me servait de source de rayons ultra-violets; les rayons calorifiques et lumineux étaient, pour la plus grande partie, absorbés par des filtres convenables.

Les milieux nutritifs dont je me suis servi en premier lieu étaient la gélose peptonée et la gélatine peptonée au petit-lait. Dans la première partie des essais, ces milieux étaient irradiés dans des tubes fermés, la source des rayons étant à environ $25 \mathrm{~cm}$. Comme

(1) BuchNer, Centralbl. für Bakter., 11, 1892.

(2) Sermfert. Die Versorgung der Grosstädte mit Kindermilch, Hamburg, 1903. 
le verre absorbe les rayons ultra-violets, la paroi des éprouvettes était en verre très mince, de $0 \mathrm{~m} / \mathrm{m} 5$ environ d'épaisseur, de façon à laisser passer la plus grande partie des rayons. Pour contrôler les effets de l'irradiation, j'ai employé parallèlement les mêmes milieux nutritifs non irradiés.

La constatation de l'effet produit par l'irradiation fut faite de la façon suivante : les milieux nutritifs furent, après l'irradiation, ensemencés de $1 \mathrm{~cm}^{3}$ de culture diluée et, après quelques jours, on dénombra sur les boîtes de Pétri le nombre des colonies formées ; on le compara à celui donné par le milieu non irradié ensemencé de la même culture. La durée de l'irradiation fut différente dans les divers essais, mais toujours assez courte. Les premiers essais furent faits avec la gélatine au petit-lait. Comme cultures, on choisit la culture de Streptococcus lactis (essais $n^{0 \mathrm{~s}} 1$ à 5 ) et celle de Streptococcus cremoris (essai $n^{\circ} 6$ ) avec des dilutions différentes. Mais, pour le même essai, on employa pour le milieu irradié et pour le milieutémoin non irradié la même dilution de la culture et la même quantité. Les résultats du dénombrement des colonies sont consignés au tableau I.

TABLEAU $\mathbf{I}$.

\begin{tabular}{c|c|c|c}
\hline \hline \multirow{2}{*}{$\begin{array}{c}\text { Numéro } \\
\text { dessais }\end{array}$} & \multicolumn{2}{|c|}{ Milieu irradié } & \multicolumn{2}{c}{ Milieu non irradié } \\
\cline { 2 - 4 } & Durée de l'irradiation & & \multicolumn{2}{c}{ Nombre des colonies } \\
\cline { 2 - 4 } 1 & & 10 & 15 \\
2 & 6 minutes & 148 & 676 \\
3 & 10 minutes & 239 & 717 \\
4 & 16 minutes & 32 & 61 \\
5 & 15 minutes & 3 & 6 \\
6 & 15 minutes & 327 & 482 \\
\hline \hline
\end{tabular}

Pour les essais suivants, j'ai utilisé la gélose au lieu de la gélatine. Le procédé de travail est resté le même ; l'ensemencement a été fait de nouveau avec les cultures diluées de Streptococcus lactis (essais 7 et 8 ) et de Streptococcus cremoris (essai no 9). On en trouvera les résultats au tableau II.

TABLEAU II.

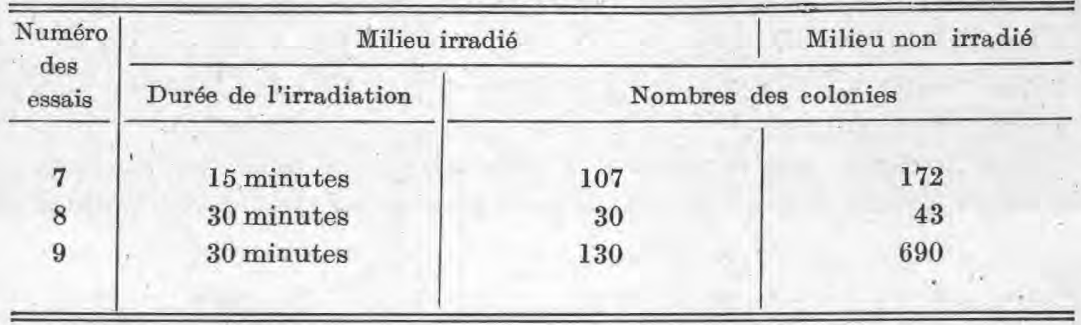


De l'examen de ces deux tableaux, il résulte que pour les deux milieux nutritifs utilisés, l'irradiation a eu un effet évident sur le nombre des colonies dénombré sur les plaques de contrôle. L'abaissement du nombre des colonies sur le milieu irradié a atteint jusqu'à plus d'un einquième (essai no 9 ) ; dans les autres cas, il était d'un quart, un demi, un tiers, deux tiers, etc. En aucun cas, on n'a trouvé un nombre de colonies plus grand que dans le milieu non irradié. Quant aux eultures employées, on n'a trouvé aucune différence entre le développement du St. lactis et celui du St, cremoris.

Les recherches suivantes sont destinées à montrer l'influence de la durée de l'irradiation. Dans les deux essais on a utilisé la gélatine peptonée ensemencée de la culture diluée de St. cremoris. La durée de l'irradiation a été la même pour les deux essais, alors que la quantité de culture, la température pendant la croissance des colonies, la durée de la végétation étaient différentes. Les résultats des recherches sont fournies par le tableau III.

TABLEAU III.

\begin{tabular}{c|c|c|c}
\hline \hline $\begin{array}{c}\text { Numéro } \\
\text { des } \\
\text { essais }\end{array}$ & \multicolumn{2}{|c|}{ Milieu irradié } & Milieu non irradié \\
\cline { 2 - 3 } 10 & 15 minutes & 30 minutes & \\
\cline { 2 - 3 } 11 & 514 & 344 & 662 \\
& 511 & 378 & 656 \\
\hline \hline
\end{tabular}

On voit clairement, par ces deux essais, que le nombre de colonies développées sur les milieux nutritifs est d'autant plus petit que la durée de l'influence des rayons ultra-violets a été plus grande.

Dans les essais suivants, le milieu nutritif fut irradié directement, dans le but d'éliminer l'influence du verre des éprouvettes, qui retient une partie des rayons ultra-violets. Le milieu utilisé fut encore la gélatine au petit-lait, doucement réchauffée dans les éprouvettes, puis versée sur les boîtes de Pétri, lesquelles, non couvertes, furent exposées aux rayons de la lampe de MülleR placée à $25 \mathrm{~cm}$. La gélatine était irradiée à l'état liquide à une température d'environ $30^{\circ} \mathrm{C}$. La boîte fut ensuite couverte et on glissa, à l'aide d'une pipette stérile, $1 \mathrm{~cm}^{3}$ de culture diluée de St. cremoris, que l'on répartit uniformément dans le milieu nutritif par un balancement de la boîte. La gélatine de contrôle fut également versée dans une boîte de Pétri et ensemencée de la même manière. Les boîtes furent conservées dans des circonstances identiques et le dénombrement effectué. Les résultats sont groupés dans le tableau IV. 
TABLEAU IV.

\begin{tabular}{c|c|c|c}
\hline \hline \multirow{2}{*}{$\begin{array}{c}\text { Numéro } \\
\text { des } \\
\text { essais }\end{array}$} & \multicolumn{2}{|c|}{ Milieu irradié } & Milieu non irradié \\
\cline { 2 - 4 } & Durée de l'irradiation & \multicolumn{2}{|c}{ Nombre des colonies } \\
\cline { 2 - 4 } 12 & 15 minutes & 63 & 97 \\
13 & 15 minutes & 257 & 332 \\
14 & 15 minutes & 260 & 302 \\
15 & I5 minutes & 195 & 410 \\
16 & 20 minutes & 1,620 & 1.920 \\
\hline
\end{tabular}

Comme on pouvait s'y attendre, les résultats de ces recherches sont d'accord avec les précédents. Le nombre de colonies développées dans les milieux nutritifs irradiés est remarquablement plus faible que celui trouvé dans les milieux non irradiés.

La recherche suivante fut çffectuée avec de la gélatine au bouillon, au lieu de petit-lait. L'irradiation dans la boîte ouverte de PÉtRI eut une durée de 15 minutes et l'ensemencement fut fait comme précédemment. Les résultats furent les suivants :

\begin{tabular}{|c|c|}
\hline \multicolumn{2}{|c|}{ Nombre de colonies } \\
\hline Milieu & Milieu \\
\hline irradié & non irradie \\
\hline 41 & 144 \\
\hline
\end{tabular}

Essai no 17

41

144

Ces résultats confirment pleinement les précédents.

Pour répondre à la question de savoir si l'irradiation directe des bactéries est plus puissante que l'irradiation du milieu nutritif, j'ai effectué les recherches suivantes :

Trois boîtes de PÉtri ont été préparées. Dans la première, de la gélatine au petit-lait, légèrement chauffée, fut soumise aux radiations ultra-violettes, puis ensemencée par $1 \mathrm{~cm}^{3}$ de culture de St. cremoris ; dans la deuxième, le même milieu fut d'abord ensemencé, puis irradié dans les mêmes conditions ; enfin, la troisième contenait le milieu-témoin non irradié et ensemencé par la méthode citée plus haut. Les résultats des essais sont indiqués au tableau $n^{\circ} \mathrm{V}$.

TABLEAU V.

\begin{tabular}{c|c|c|c}
\hline \hline \multirow{2}{*}{$\begin{array}{c}\text { Numéro } \\
\text { des } \\
\text { essais }\end{array}$} & \multicolumn{2}{|c|}{ Milieu irradié } & Milieu non irradié \\
\cline { 2 - 4 } & avant l'ensemencement & après l'ensemencement & \\
\cline { 2 - 4 } 18 & 195 & 145 & 425 \\
19 & 71 & 66 & 194 \\
\cline { 2 - 4 } & & Nombre des colonies & \\
\hline \hline
\end{tabular}


On voit que l'effet de l'irradiation est plus grand lorsque le milieu nutritif est ensemencé avant de subir l'action des rayons ultra-violets. Il est vraisemblable que dans ce cas, il y a deux influences qui s'ajoutent : l'action directe des radiations sur les bactéries et leur action sur le milieu nutritif lui-même. Ces essais viennent en outre confirmer les résultats des recherches précédentes.

Pour toutes les recherches effectuées jusqu'ici, j'ai utilisé, pour l'ensemencement, des cultures de St. lactis ou de St. cremoris. Il était intéressant de rechercher si les effets de l'irradiation se feraient sentir de la même manière sur d'autres microorganismes. J'ai employé à cet effet des cultures diluées du Bacterium coli commune, de Sarcina lutea et de Torula lactis. Les milieux utilisés, la méthode d'irradiation et les procédés d'ensemencement furent les mêmes que lors des essais précédents. Dans les recherches $n^{\circ s} 20,21$ et 22, les milieux nutritifs furent ensemencés avec $1 \mathrm{~cm}^{3}$ de culture diluée de Bacterium coli commune, dans les nos 23 et 24 avec Sarcina lutea et dans les $n^{\circ s} 25$ et 26 avec Torula lactis. Le tableau no VI donne les résultats de ces recherches.

TABLEAU VI.

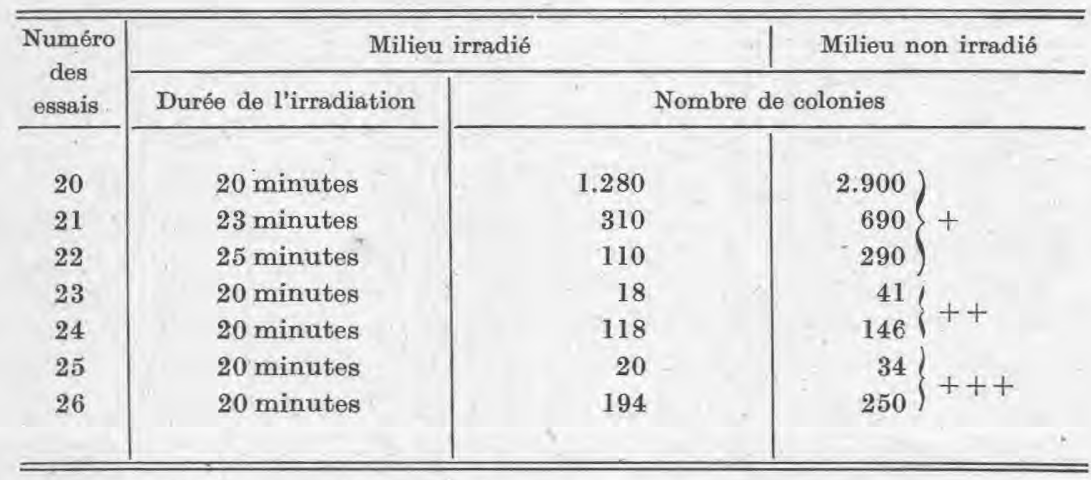

$+\quad$ Bacterium coli commune.

++ Sarcina lutea.

+++ Torula lactis.

Ces résultats montrent que l'irradiation de la gélatine au petitlait par les rayons ultra-violets a pour effet d'abaisser considérablement le nombre des colonies des autres bactéries et même des autres microorganismes, comme des levures du genre Torula. Ces résultats concordent parfaitement avec ceux que nous avons obtenus avec l'ensemencement par des streptocoques.

Toutes les recherches précédentes ont été réalisées en irradiant des milieux nutritifs solides. Dans la dernière série de recherches, j'ai utilisé le lait comme milieu nutritif à irradier. $100 \mathrm{~cm}^{3}$ de lait 
ont été pasteurisés chaque fois dans des boîtes à parois verticales, férmées par un couvercle en verre. Pour chacun des essais, j'ai employé deux boîtes parfaitement identiques et, après refroidissement, le lait de l'une des boîtes était irradié par les rayons ultraviolets, le couvercle ayant été enlevé pour faciliter le libre accès des rayons. Le lait de la seconde boîte, non irradié, était conservé comme témoin, puis les deux boîtes étaient ensemencées d'une même quantité $\left(1 \mathrm{~cm}^{3}\right)$ de culture pure de $S t$. lactis et abandonnées au repos dans les mêmes conditions. Au bout de quelque temps, on déterminait, simultanément, l'acidité (exprimée en degrés SoxhletHenkel) du lait de chacune des boîtes. Cette acidité comparée devait permettre de juger de l'influence de l'irradiation sur le lait. Les recherches ont été faites, soit avec du lait écrémé (essais nos 27 à 31 ), soit avec du lait non écrémé (essais nos 32 à 34). Les résultats sont réunis dans le tableau VII.

TABLEAU VII.

\begin{tabular}{|c|c|c|c|c|}
\hline \multirow{2}{*}{$\begin{array}{c}\text { Numéro } \\
\text { des } \\
\text { essais }\end{array}$} & Milieu & radié & Milieu non irradié & \multirow{2}{*}{$\begin{array}{l}\text { Différence } \\
\text { d'acidité }\end{array}$} \\
\hline & $\begin{array}{c}\text { Durée } \\
\text { de l'irradiation }\end{array}$ & \multicolumn{2}{|c|}{ Acidité en degrés Soxhlet-Henkel } & \\
\hline 27 & 15 minutes & 25,1 & 25,3 & 0,2 \\
\hline 28 & 15 minutes & 18,7 & 21,1 & 2,4 \\
\hline 29 & 15 minutes & 33,0 & 33,8 & $0,8\}+$ \\
\hline 30 & 15 minutes & 25,3 & 26,6 & 1,3 \\
\hline 31 & 15 minutes & 24,0 & 25,3 & 1,3 \\
\hline 32 & 15 mimutes & 17,1 & 24,8 & 7,7 \\
\hline 33 & 25 minutes & 11,8 & 12,8 & $1,0\}++$ \\
\hline 34 & 30 minutes & 11,6 & 13,6 & $2,0)$ \\
\hline
\end{tabular}

+ Lait non écrémé.

+ + Lait écrémé.

En comparant le degré d'acidité du lait irradié à celui du lait non irradié, on voit que dans tous les cas, le premier est inférieur au second, preuve que dans le lait irradié la multiplication des bactéries a été un peu plus faible. Mais les différences d'acidité sont en général assez faibles, sauf dans un seul cas (essai no 32 ). Les résultats sont les mêmes pour le lait non écrémé et pour le lait écrémé.

Comme la couche de lait, exposée aux rayons dans la boîte, avait une épaisseur d'environ $1 \mathrm{~cm}, 6$, on pouvait supposer que la faible influence de l'irradiation sur l'acidité du lait était due au fait que les rayons pouvaient difficilement agir en profondeur. J'ai done fait de nouveaux essais dans lesquels les couches de lait n'avaient 
que $4 \mathrm{~m} / \mathrm{m}$ d'épaisseur. Les résultats n'ont pas été différents des précédents, comme on peut le voir au tableau VIII.

TABLEAU VIII.

\begin{tabular}{|c|c|c|c|c|}
\hline \multirow{2}{*}{$\begin{array}{c}\text { Numéro } \\
\text { des } \\
\text { essais }\end{array}$} & \multicolumn{2}{|c|}{ Milieu irradié } & Milieu non irradié & \multirow{2}{*}{ Différence } \\
\hline & $\begin{array}{c}\text { Durée } \\
\text { de l'irradiation }\end{array}$ & \multicolumn{2}{|c|}{ Acidité en degrés S.-H. } & \\
\hline 35 & 15 minutes & 18,5 & 20,0 & 1,5 \\
\hline 36 & 15 minutes & 19,2 & 20,5 & 1,3 \\
\hline 37 & 15 minutes & 16,8 & 18,8 & 2,0 \\
\hline
\end{tabular}

Ainsi, les rayons ultra-violets produisent dans le lait, comme dans les milieux nutritifs étudiés précédemment, mais dans une mesure moindre, certains changements d'où résulte une diminution dans le développement des bactéries.

En résumé, on peut dire que dans tous les milieux bactériologiques qui ont été examinés, l'irradiation par les rayons ultraviolets produit des modifications qui amènent un ralentissement de la multiplication des bactéries et des levures. Ces modifications sont d'autant plus prononcées que la durée de l'irradiation est plus longue. L'influence des rayons ultra-violets est très marquée sur les milieux nutritifs solides; elle s'est montrée beaucoup plus faible sur le lait écrémé et sur le lait non écrémé.

\title{
LES ANIMAUX COMIME CORPS ÉTRANGERS DANS LE LAIT (1)
}

\author{
par
}

le Dr F. G. KOHN.

(Administration du Marché municipal de Karlsbad. Président : Dr Messner, Professeur.)

On sait que la mamelle, et plus encore son produit, le lait, constituent un milieu très favorable pour le développement des schizomycètes, mais on ne sait pas grand'chose des rapports permanents qui existent entre les animaux et la glande mammaire ainsi qu'avec le lait. Les échinocoques, qui figurent [1] parmi les parasites de la glande mammaire, ne peuvent pas être rendus responsables d'une infection du lait, car, habitant l'interstitium, ils sont isolés du tissu glandulaire par une enveloppe imperméable.

(1) Traduction de M. C.WoLf, d'un article de Prager Archiv für Tiermedizin, XII, 1932. 